\title{
PARQUES URBANOS NO MUNICÍPIO DE SÃO PAULO - SP (BRASIL): ESPACIALIZAÇÃO E DEMANDA SOCIAL.
}

\author{
Msc. GIORGIA LIMNIOS* \\ Mestre em Ciências pelo Programa de Pós-Graduação em Geografia Física da Faculdade de Filosofia, \\ Letras e Ciências Humanas - Universidade de São Paulo/USP - Brasil. E-mail: giorgiageo@usp.br \\ DRA. SUELI ÂNGELo FURLAN** \\ **Professora do Departamento de Geografia da Faculdade de Filosofia, Letras e Ciências Humanas - Uni- \\ versidade de São Paulo/USP - Brasil. E-mail: sucaangf@usp.br
}

\section{RESUMO}

O parque urbano é um produto da cidade da era industrial. Nasceu a partir do século XIX, da necessidade de dotar as cidades de espaços adequados para atender a uma nova demanda social: o lazer, o tempo do ócio e para contrapor-se ao ambiente urbano edificado (MACEDO, 2003). O município de São Paulo possui parques em todos os setores da cidade e para entender se existe proporcionalidade desses espaços com os outros tipos de uso da terra, definiu-se o limite municipal como área de estudo. Os parques urbanos municipais e estaduais existentes foram classificados segundo as seguintes categorias de espaços livres: parques de vizinhança, parques de bairro, parques setoriais e parques regionais, conforme o dimensionamento das unidades e raio de atendimento à população (CAVALHEIRO, 1992; KLIASS, 1993).

Palavras-chave: parque urbano, demanda social, área de influência, ordenamento territorial, planejamento ambiental.

\section{URBAN PARKS IN THE CITY OF SÃO PAULO - SP (BRAZIL): SPATIALIZATION AND SOCIAL DEMAND.}

\begin{abstract}
The urban park has its origin in the cities during the industrial era. It started in the 19th century, due to the need to provide cities with adequate spaces to satisfy a new social demand: leisure, idle time and to counteract the urban built environment (Macedo, 2003). There are parks in all regions of the city in São Paulo and to understand if there is propor-
\end{abstract}


tionality of these spaces with other types of land use, it was defined the municipal boundary as the area to be analyzed. The existing urban municipal and state parks were classified according to the following categories of open spaces: neighborhood parks, district parks, sector parks and regional parks, according to the size of the units and the serving radius to the population (CAVALHEIRO, 1992; Kliass, 1993).

Keywords: urban park; social demand; area of influence; territorial planning; environmental planning.

O potencial paisagístico da cidade de São Paulo, caracterizado por sua estrutura física, correspondente às colinas e várzeas, densa rede hidrográfica e cobertura vegetal florestal e campestre foram elementos pouquíssimos considerados no desenvolvimento urbano quando a questão se refere à criação de parques. O rápido crescimento da área urbana de São Paulo, notadamente a partir do início do século XX, não foi acompanhado por um plano de áreas verdes que atendesse à demanda social por espaços de recreação, lazer e descanso, além das funções culturais, ambientais e sociais intrínsecas das áreas verdes urbanas. "A cidade se expandiu transformando significativamente as características geoecológicas do seu sitio urbano e, vários estudos sobre a expansão urbana demonstram o espalhamento da cidade por todos os tipos de terrenos (FURLAN, 2004).

Poucos são os parques urbanos de São Paulo que foram criados a partir das potencialidades naturais da cidade. A cobertura vegetal existente nas colinas paulistanas, no divisor de águas entre os vales dos rios Tietê e Pinheiros, hoje muito bem marcado pelo eixo viário da avenida Paulista, foi o elemento natural considerado na criação do atual Parque Tenente Siqueira Campos (1892). Nessa região de São Paulo "Araucárias, isoladas ou em bosquetes, emergiam acima do dossel das matas tropicais atlânticas de Planalto".(Ab' SABER, 2004).

Quando os viajantes naturalistas e botânicos estudaram a cidade de São Paulo, em suas expedições científicas no século XIX, estes encontraram uma paisagem muito diferente da atual. Na passagem pela cidade e seus arredores observaram que esta estava estruturada espacialmente nas colinas e várzeas das duas bacias hidrográficas principais: os rios Tietê e Pinheiros. Usteri (1911) esboçou um dos poucos mapas dessa distribuição (Figura 1). A cobertura vegetal que circundava a mancha urbana era formada por um mosaico caracterizado pelo encontro de floras da Floresta Tropical Pluvial Atlântica, Cerrados e Campos. Nos relatos da viagem feita pelos naturalistas Spix \& Von Martius à essa cidade, eles assinalaram que ... "São lindas as cercanias de São Paulo, embora de aspecto mais terrestre do que as do Rio de Janeiro. A ausência do espetáculo grandioso do mar e das montanhas maciças 
fica compensada pelo panorama do extenso território que oferece toda a variedade possível de campinas verdejantes e frondosas matas, colinas alternantes com bonitos vales". Outro importante naturalista que muito escreveu sobre São Paulo foi o botânico Auguste de Saint- Hilaire. Em viagem pela província de São Paulo no início do século XIX, por volta de 1816, vindo do Rio de Janeiro ele descreve as formações fitogeogáficas dessa região. Assim como outros pesquisadores do assunto, Saint-Hilaire observou que a cobertura vegetal se caracterizava como um mosaico de duas cores verdes bem recortadas onde o tom mais suave se espalhava pela planície coberta por campos e o tom mais forte das matas estava distribuído em pontos próximos uns dos outros localizados nas colinas. Havia tantos fragmentos de matas quanto áreas cobertas por campos e para esse pesquisador era difícil determinar qual formação predominava nos arredores de São Paulo (LIMNIOS, 2006).

Desconsiderando seus importantes suportes naturais a cidade foi se estruturando a partir de tecnologias cada vez mais sofisticadas para verticalizar, adensar, implantar sistema viário complexo, aterrando e drenando áreas úmidas, mudando cursos dos rios, canalizando e retificando meandros, drenando e rebaixando lençol freático, removendo a vegetação nativa, eliminando o solo, desmontando o relevo, entre outros (FURLAN, 2004). Diante das grandes mudanças ocorridas no uso da terra, poucas áreas com características naturais relevantes para a conservação e uso social.

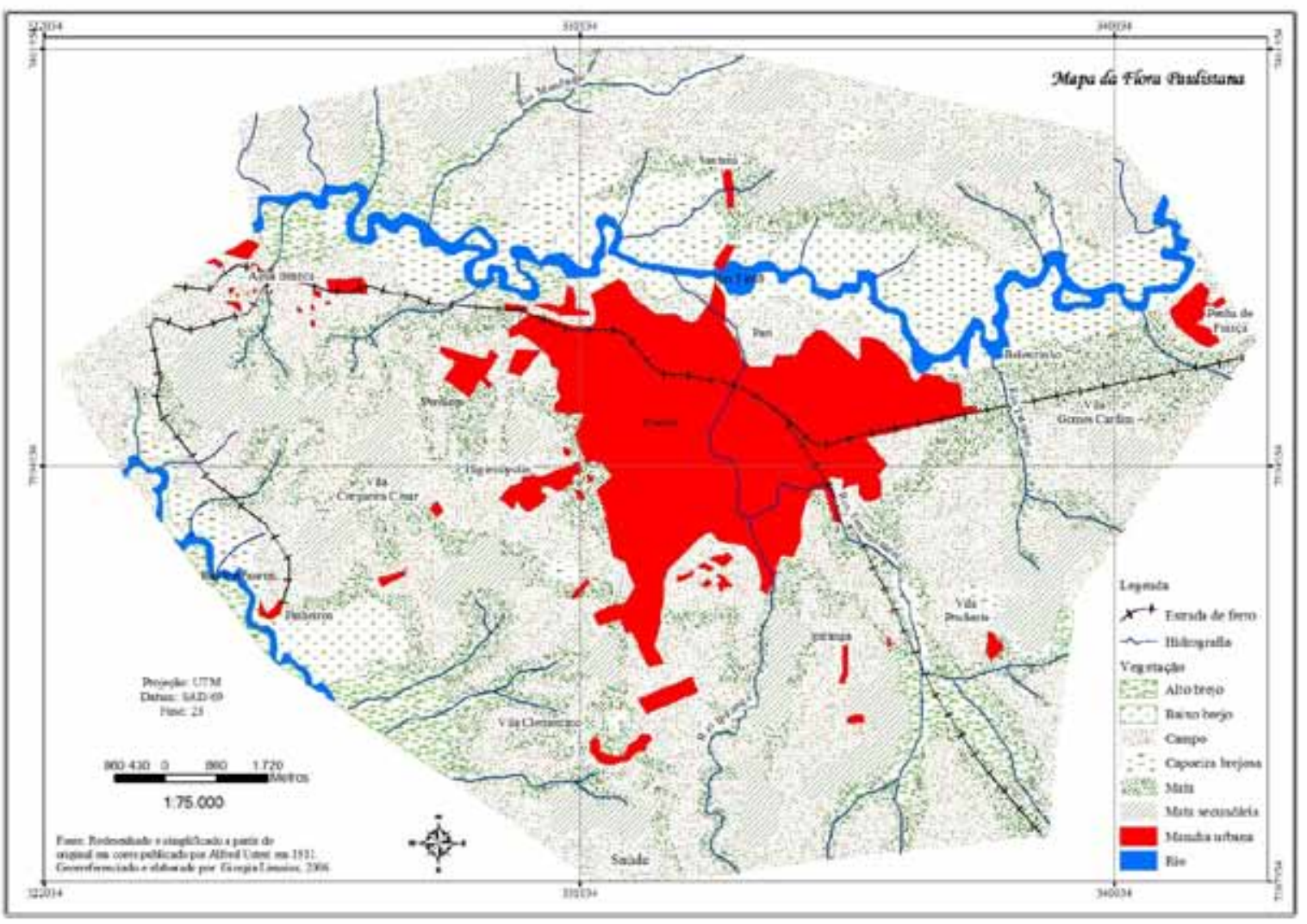

Figura 1 - Mapa da Flora Paulistana (1911). Autor: Alfred Usteri.

Georreferenciado e organizado por Giorgia Limnios, 2006. 
Os rios e suas várzeas e alagadiços eram muitos utilizados como vias de deslocamento, assim como o lazer da população e prática de esportes. A configuração morfológica de São Paulo e seu clima favoreceu a existência desse recurso natural, que era muito abundante, conforme fora mapeado nas antigas plantas da cidade (Figura 2). Foi nesse cenário que se implantou a Ilha dos Amores, entre a atual rua 25 de março e o Rio Tamanduateí, em meados na segunda metade do século XIX, na tentativa de sanear e dar uso de parque urbano a esse setor da cidade. Porém, mesmo antes das obras de retificação e canalização do rio até sua foz, a ilha fluvial foi abandonada por volta de 1888. Após essa tentativa frustrada de destinação da várzea, que já apresentava alguns problemas ambientais, principalmente pela poluição das águas e, sociais, como as enchentes, tem-se novos esforços na gestão de Raimundo Duprat, quando o prefeito convidou o engenheiro-paisagista francês Joseph Antoine Bouvard a avaliar os planos de melhoramentos urbanos e viários elaborados para a cidade. Entre as recomendações do engenheiro estava a criação de um grande parque na Várzea do Carmo e em relatório datado de 15/05/1911 descreve: "Finalmente no que respeita ao augmento da cidade, ao desenvolvimento inevitável, certo e rápido, já indiquei o systema que considero o melhor, direi quase o único aceitável no estado actual de coisas. Em todas essas disposições cumpre não esquecer a conservação e criação de espaços livres, de centros de vegetação, de reservatórios de ar. Mais a população augmentará, maior será a densidade de agglomeração, mais crescerá o numero de construcções, mais alto subirão os edifícios, maior se imporá a urgência de espaços livres, de praças públicas, de squares, de jardins, de parques, se impõe....”(apud KLIASS, 1993).
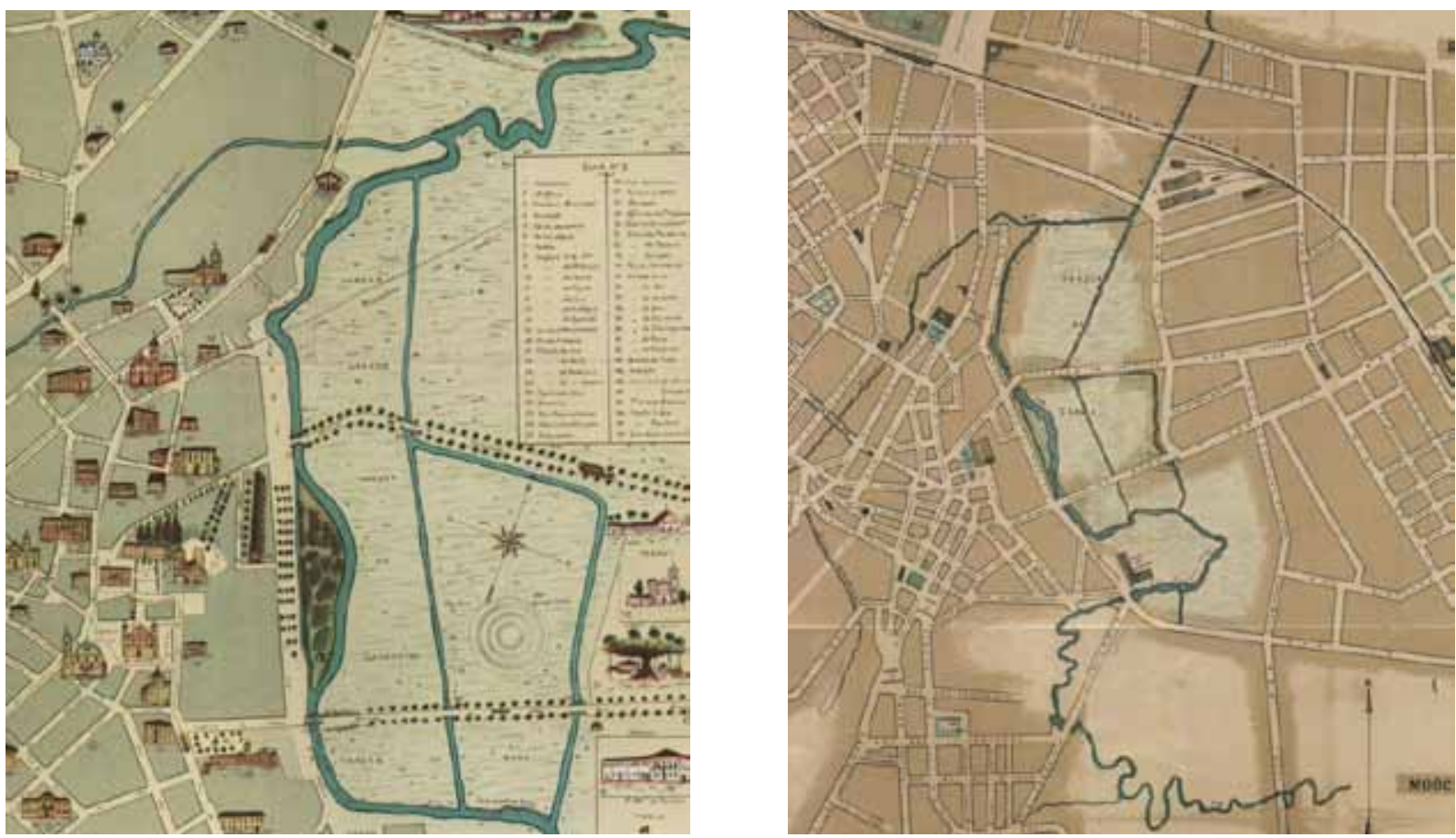

Figura 2 e 3 - Da esquerda para a direita: Mapa da Capital da Província de São Paulo, 1877. Planta da Capital do Estado de São Paulo, 1890. 
As obras de implantação do parque tiveram início no ano de 1918 e foram concluídas no final de 1920/início de 1921 sendo a denominação oficial do parque como Dom Pedro II. Porém, todos os esforços de aproveitamento desse espaço, de difícil ocupação humana, resultaram na efemeridade da existência do parque, substituída no período das políticas rodoviaristas por largas avenidas e complexo sistema viário na década de 1960, conforme estava previsto no Plano de Avenidas de 1938.

Atualmente, existe no município de São Paulo somente 1 parque urbano, de administração do Estado, que conserva essa tipologia de ambiente (várzea). Alguns parques lineares vem sendo implantados com função estabilizadora das inundações e também de lazer. Na região sul do município recentemente a prefeitura vem investindo na criação de Unidades de Conservação para preservação das várzeas com Mata Paludosa, uma fitofisionomia hoje rara no município.

O parque urbano é um produto da cidade da era industrial. Nasceu a partir do século XIX, da necessidade de dotar as cidades de espaços adequados para atender a uma nova demanda social: o lazer, o tempo do ócio e para contrapor-se ao ambiente urbano edificado (MACEDO, 2003). O parque urbano brasileiro, ao contrário do seu congênere europeu, não surge da urgência social de atender às necessidades das massas urbanas da metrópole do século XIX. Nesse século, o Brasil não tinha uma rede urbana expressiva, e nenhuma cidade, inclusive a capital, o Rio de Janeiro, tinha o porte de qualquer grande cidade europeia da época, sobretudo no que diz respeito a população e área. O parque urbano é então criado, como uma figura complementar ao cenário das elites emergentes, que controlavam a nova nação urbana em formação e que procuravam construir uma figuração urbana compatível com a de seus interlocutores internacionais, especialmente ingleses e franceses. Os jardins botânicos, concebidos inicialmente como centros de pesquisa da flora tropical, foram instalados nas principais aglomerações urbanas a partir do final do século XIX, à margem do núcleo central. Sua criação foi o resultado de um aviso régio de 17 de novembro de 1798, que, juntamente com a Carta Regia de 1796, estabeleceu uma política de criação de uma série de estabelecimentos botânicos na colônia, a fim de proporcionar as bases de um intercâmbio de plantas úteis à economia portuguesa. Uma parte deles desapareceu no decorrer do século $\mathrm{XIX}$ e, à medida que diminuiu o interesse pela pesquisa, outros assumiram uma função mista de parque urbano e de pesquisa, enquanto outros se transformaram totalmente em parques (MACEDO, 2003). 
O Jardim Botânico de São Paulo, por exemplo, transforma-se, não muitos anos após sua inauguração, em parque público (1825), e no decorrer do século é totalmente adaptado a essa função, tornando-se ponto de encontro dos barões de café e seus associados. Posteriormente denominado Jardim da Luz, constituiu um parque urbano de alta qualidade projetual, estruturado em grandes eixos clássicos e com vegetação composta por espécies temperadas européias (MACEDO, 2003).

Podemos classificar o surgimento dos parques urbanos em três movimentos. O primeiro deles, concentrado entre o final do século XIX e início do século XX, foi marcado pelo incremento da economia cafeeira e pela transformação do antigo burgo na grande cidade que é São Paulo. Naquele momento, os parques, de inspiração largamente francesa, eram criados como locais de cultura, pontos de encontro para a sociedade paulistana. Neste movimento, surgiram parques como Jardim da Luz, Praça Buenos Aires e Tenente Siqueira Campos (antigo Trianon), sendo o Ibirapuera o último grande parque criado dentro desta perspectiva (ISA, 2008).

Um segundo movimento, detectado quando a cidade já alterara significativamente sua fisionomia e transformara-se, de fato, numa metrópole, coloca a criação de parques a partir de remanescentes de grandes fazendas, chácaras e propriedades da elite paulistana, caso de parques como Carmo e Piqueri (ISA, 2008)..

Por fim, o movimento atual traz a real necessidade de proporcionar a criação de novas áreas, em especial nas periferias da cidade, onde ela continua a crescer a altas taxas demográficas. É neste ponto que detectamos o surgimento de parques muitas vezes pequenos em extensão, no entanto profundamente necessários para proporcionar melhor qualidade de vida aos paulistanos. Esta realidade vem desde a década de 1970 e se estende aos dias de hoje, quando há um grande esforço das políticas públicas em ampliar o número de parques na cidade. Momento em que o poder público municipal investe na criação, inclusive, dos chamados Parques Lineares, buscando ao mesmo tempo ampliar a área verde municipal, melhorar a qualidade de vida da população e evitar problemas com o escoamento da água em época de chuvas e conter o risco socioambiental da ocupação das margens de córregos urbanos (ISA, 2008).

Recuperar fundos de vales dos rios e córregos da cidade por meio da implantação de áreas de lazer, saneamento e limpeza dos rios. Este é o objetivo primeiro dos chamados Parques Lineares. Sua implantação, determinada pelo Plano Diretor da Cidade (2004), propiciará a conservação das Áreas de Proteção Permanente (APPs) 
instituídas pelo Novo Código Florestal (Lei Federal n 12.651/2012 ) que margeiam os cursos d'água e minimizará os efeitos negativos das enchentes que assolam São Paulo (ISA, 2008).

\section{BANDEIRA DA QUALIDADE DE VIDA: O PROGRAMA 100 PARQUES}

Não é novidade a afirmação de que a expansão da periferia urbana é um indicador do afluxo de pessoas de mais baixa renda em loteamentos irregulares sem infraestruturas, reforçando o ciclo vicioso da pobreza. Essas ocupações estão em locais onde se localizavam originalmente chácaras e sítios, especialmente nos contrafortes face sul da Cantareira e na região das represas ao sul da cidade de São Paulo na região conhecida como Parelheiros, e atingem áreas de mananciais (MELLO-THÉRY, 2011).

O programa 100 parques é uma política que priorizou essencialmente o potencial paisagístico e isto foi uma inovação na visão das funções ecológicas, de lazer e estética das áreas verdes no município de São Paulo. No entanto, quais são as atribuições e os atributos de um parque urbano? Os principais elementos para um parque urbano são a sua geografia física, a sua função urbana e o relacionamento com seu entorno, segundo Kliass (1993). Atualmente essa visão de contexto deve ter como referencia estudos urbanísticos, paisagísticos e da ecologia de paisagens. Um tripé novo no planejamento da criação de parques e unidades de conservação urbanas.

\section{METODOLOGIA DO ESTUDO}

Para entender se existe proporcionalidade desses espaços com os outros tipos de uso da terra, definiu-se o município de São Paulo como área de estudo e os parques urbanos municipais e estaduais existentes foram classificados segundo as seguintes categorias de espaços livres: parques de vizinhança, parques de bairro, parques setoriais e parques regionais, conforme o dimensionamento das unidades e raio de atendimento à população (CAVALHEIRO, 1992; KLIASS, 1993). Para os parques de vizinhança foram sugeridos área mínima de $5000 \mathrm{~m}^{2}$ e raio de influência correspondente a 1000 metros de distância; os parques de bairro devem possuir área mínima de 10 ha e raio de influência de 1000 metros ou 10 minutos a pé, os parques setoriais devem possuir área mínima de 100 ha e estar distante 1200 metros da residência ou no máximo 30 minutos/veículo e os parques regionais devem possuir 200 ha e corpos 
d' água e estar localizados em qualquer parte da cidade. Esses valores devem ser entendidos como indicativos à capacidade de suporte para visitação dos espaços relacionados, o quanto de equipamentos podem conter e a maximização de sua manutenção (CAVALHEIRO, 1992). Com o auxílio de ferramentas de Sistemas de Informações Geográficas, por meio do software ArcGIS 9.3, foi possível estabelecer as áreas de influência dos parques existentes e verificar a necessidade de implantação de novos espaços livres destinados ao uso de uma parcela da população não atendida; a partir de dados demográficos dos 96 distritos existentes no município de São Paulo elaborado pelo Instituto Brasileiro de Geografia e Estatística no ano de 2000. O uso dessa ferramenta também possibilitou visualizar essas informações em todos os setores da urbe e planejar os espaços com maior eficiência.

\section{RESULTADOS E CONCLUSÕES}

O município de São Paulo (capital do Estado de mesmo nome) apresenta uma área de $1523 \mathrm{~km} 2$. Desses, aproximadamente $870 \mathrm{~km}$ corresponde à área urbanizada, onde vivem cerca de $65 \%$ da população, estimada atualmente em cerca de 10.659 .386 habitantes (IBGE, 2010) .

Muitos dos problemas socioambientais que ocorrem na cidade da atualidade demonstram que a cidade cresceu acima de suas condições de absorver impactos decorrentes de sua estruturação urbana (FURLAN, 2004). E o processo construtivo sem reservas de espaços livres como reserva fundiária para a criação de parques urbanos é reflexo disto.

As análises espaciais elaboradas neste estudo demonstram que o uso da cobertura vegetal como suporte ao planejamento ambiental urbano vem sendo pouco utilizado e seriam de enorme valia na busca de maior eficiência nas funções previstas para parques urbanos.

Estudos realizados no início da década de 1990, pela Secretaria Municipal de Planejamento - SEMPLA indicaram um total de $31,3 \mathrm{~km}$ de áreas destinadas ao estabelecimento de áreas verdes, entretanto cerca de $10,6 \mathrm{~km}$ eram efetivamente ocupados por praças, canteiros, etc. Do restante, $5 \mathrm{Km}$ encontram-se vazios e $15,7 \mathrm{~km}$ foram ocupados por outros usos, sendo $10 \mathrm{~km}$ por favelas (Atlas ambiental do município de São Paulo, 2002). 
Para análise a área de influência dos parques urbanos municipais e sua relação com os remanescentes da cobertura vegetal foram gerados três produtos cartográficos representando:

1. Área de influência dos parques urbanos e densidade demográfica por distritos no Município de São Paulo (Mapa 1)

2. Área de influência dos parques urbanos e cobertura vegetal do município de São Paulo (Mapa 2)

3. Mapa de propostas para o planejamento de parques urbanos considerando sua área de influência. (Mapa 3)

Considerando a setorização da cidade e o Mapa 1 observamos que a área central da cidade, mais densamente povoada é a que possui a maioria das tipologias de parques em número, mas não em área. Nesta não foram implantados grandes parques regionais (com 200ha de extensão). De modo geral, a maioria dos parques urbanos, em qualquer tipologia analisada, estão concentrados nas regiões central, oeste e leste, apesar de alguns distritos muito populosos da Zona Leste como Itaquera, Arthur Alvim, São Miguel Paulista não possuírem nenhuma modalidade dos parques analisados. Na região central com melhor infraestrutura de acessos por transporte público predominam parques de vizinhança. Chama a atenção a Zona Sul com total ausência de parques para qualquer tipologia, com apenas um parque de vizinhança. É uma área com grandes fragmentos da vegetação original e que apesar de extensa tem uma ocupação urbana fragmentada e carente de vários serviços públicos, dentre estes particularmente espaços livres para lazer.

O gráfico 1 apresenta o percentual das tipologias do parques urbanos existentes e abertos ao público, sendo 80 de administração municipal e 06 de administração estadual, assim distribuídos: 54 parques de vizinhança, 27 parques de bairro, 3 parques setoriais e 2 parques regionais, totalizando 86 unidades.

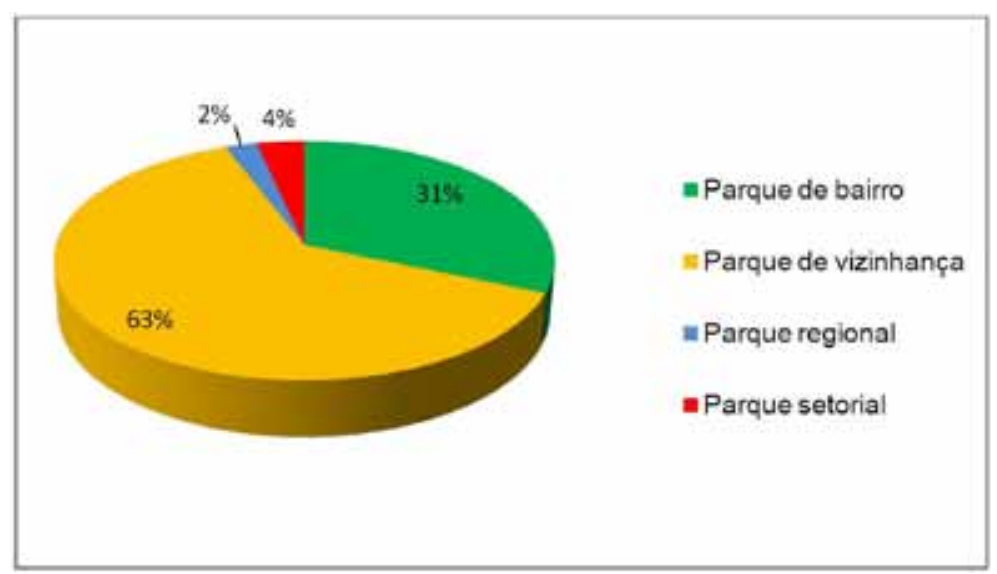

Gráfico 1 - Percentual da tipologias de parques urbanos no município de São Paulo. Fonte: SVMA. Org. Giorgia Limnios, 2013. 


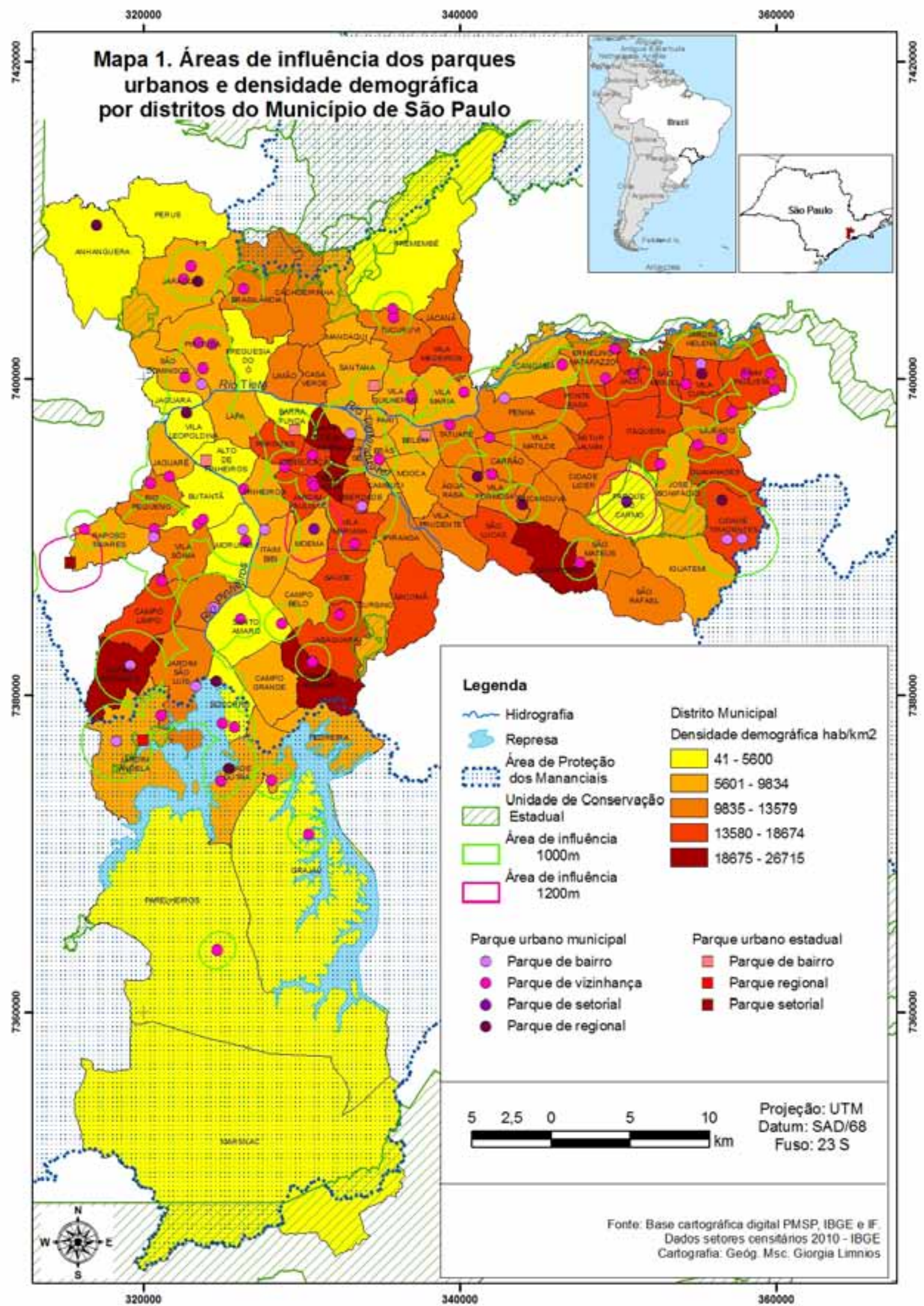

Mapa 1 - Áreas de influência dos parques urbanos e densidade demográfica por distritos no município de São Paulo 
Atualmente tem havido diversos esforços por parte do poder público municipal para implementação de um sistema significativo de parques e jardins. No ano de 2005 a cidade possuía 34 parques municipais totalizando 15 milhões de $\mathrm{m}^{2}$ de áreas protegidas municipais. Em 2009 esses números subiram para um total de 60 parques e uma soma de áreas correspondente a 24 milhões de $\mathrm{m}^{2}$, e a meta para 2012 era atingir 100 parques somando uma área corresponde a 50 milhões de $\mathrm{m}^{2}$ (Secretaria do Verde e do Meio Ambiente, Programa 100 Parques, 2012). Meta não atingida conforme dados oficiais.

Mas qual a importância da distribuição espacial e da tipologia de parques no ambiente urbano? Observando os dados da tabela 1 e do gráfico 1 é possível perceber que em muitas regiões apesar do grande número áreas verdes, a área total ainda é baixa se comparada às zonas Norte e Sul.

Tabela 1 - Número e área (ha) das áreas protegidas públicas do município de São Paulo, divididos por zonas (fonte: SVMA, org. por Lara C. C. Costa, 2012).

\begin{tabular}{|l|c|c|c|c|c|}
\hline Zona & Pqs. Urbanos & APAS & $\begin{array}{c}\text { Res. } \\
\text { Ecológicas }\end{array}$ & UCs Estaduais & Área (ha) \\
\hline Norte & 16 & 0 & 0 & 3 & $5.893,5$ \\
\hline Sul & 21 & 2 & 6 & 2 & $48.502,9$ \\
\hline Centro & 3 & 0 & 0 & 0 & 26,4 \\
\hline Leste & 25 & 1 & 2 & 1 & $4.922,8$ \\
\hline Oeste & 21 & 1 & 1 & 0 & 134,3 \\
\hline Total & 86 & 4 & 9 & 6 & $63.189,3$ \\
\hline
\end{tabular}

Há que se considerar ainda os dados da densidade demográfica. No mapa 1 temos a região sul do município com baixa densidade populacional. Vemos que a maioria dos parques está situada nas áreas de maior densidade demográfica. No entanto a Zona Leste é uma das maiores da cidade, e possui também uma das maiores concentrações populacionais, e o número e tipologia de parques é bem menor do que nos setores central, oeste e sul. 
Segundo dados da Fundação Seade do ano de 2004, a Zona Leste é a região que apresenta mais bairros atingindo a máxima densidade demográfica superior a $15.000 \mathrm{hab} / \mathrm{km}^{2}$. A única área da zona leste que apresenta os menores dados de densidade demográfica, de até 4.500 hab/km², corresponde à área de Reserva Ecológica da Fazenda do Carmo, a maior área de proteção da região.

Já nas regiões norte e sul, além de um número elevado de áreas verdes, apresentam um total em área superior às demais regiões do município, devido à presença dos grandes contínuos florestais da Serra da Cantareira na Zona Norte, e da Serra do Mar na Zona Sul.

A Zona Sul possui seis reservas ecológicas e duas áreas de proteção ambiental, as maiores do município, Capivivari-Monos com 25.100 ha e Bororé-Colônia com 9.000 ha. É também a região que apresenta as menores taxas de densidade demográfica, tendo poucos distritos que apresentam densidade demográfica superior a $15.000 \mathrm{hab} / \mathrm{km}^{2}$, enquanto os demais distritos apresentam uma média de $8.000 \mathrm{hab} / \mathrm{km}^{2}$. Nesta região a tipologia e área de influência dos parques urbanos é menor.

A Zona Norte não apresenta um número alto em relação à quantidade de unidades, porém em relação á área é uma das maiores do município. Quanto à densidade demográfica a

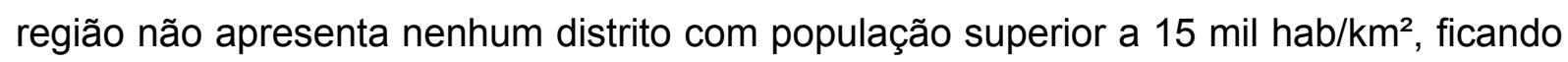
na media entre 8.000 e $11.000 \mathrm{hab} / \mathrm{km}^{2}$.

Em relação à zona oeste, se comparada as demais zonas da cidade, esta apresenta uma baixa concentração tanto em relação a quantidade de unidades quanto em área total, mas apresenta também menores dados de densidade demográfica, ficando na média de 8.000 hab/km².

Já a área central da cidade por apresentar a urbanização mais consolidada, tem uma carência grande de áreas verdes, apresentando apenas três parques de áreas relativamente pequenas. Em relação a sua densidade demográfica apresenta áreas mais densamente povoadas com população superior a $15.000 \mathrm{hab} / \mathrm{km}^{2}$, mas também áreas menos densamente ocupadas ficando na média de $11.000 \mathrm{hab} / \mathrm{km}^{2}$.

A partir desses dados é possível observar que a maior concentração de parques, APAs, e Reservas Ecológicas estão concentradas na zona sul do município, apresentando assim consequentemente a maior cobertura vegetal, enquanto em regiões como o centro e a zona leste apresentam as menores porcentagens de áreas protegidas e parques urbanos

No mapa 2 procurou-se esboçar a distribuição da tipologia de parques urbanos numa base com os remanescentes da cobertura vegetal. As fitosonomias campestres do município são minimamente representadas nos Parques Urbanos. Há uma mentalidade institucional que parques e jardins devem conter fitofisomias arbóreas e ou ainda uma paisagis- 
mo baseado em plantas exóticas. Podemos dizer que alguns parques de bairro na zona oeste, leste e norte do município representam a dimensão ecológica dos parques urbanos conservando em seu perímetro fragmentos remanescentes da Mata Atlântica

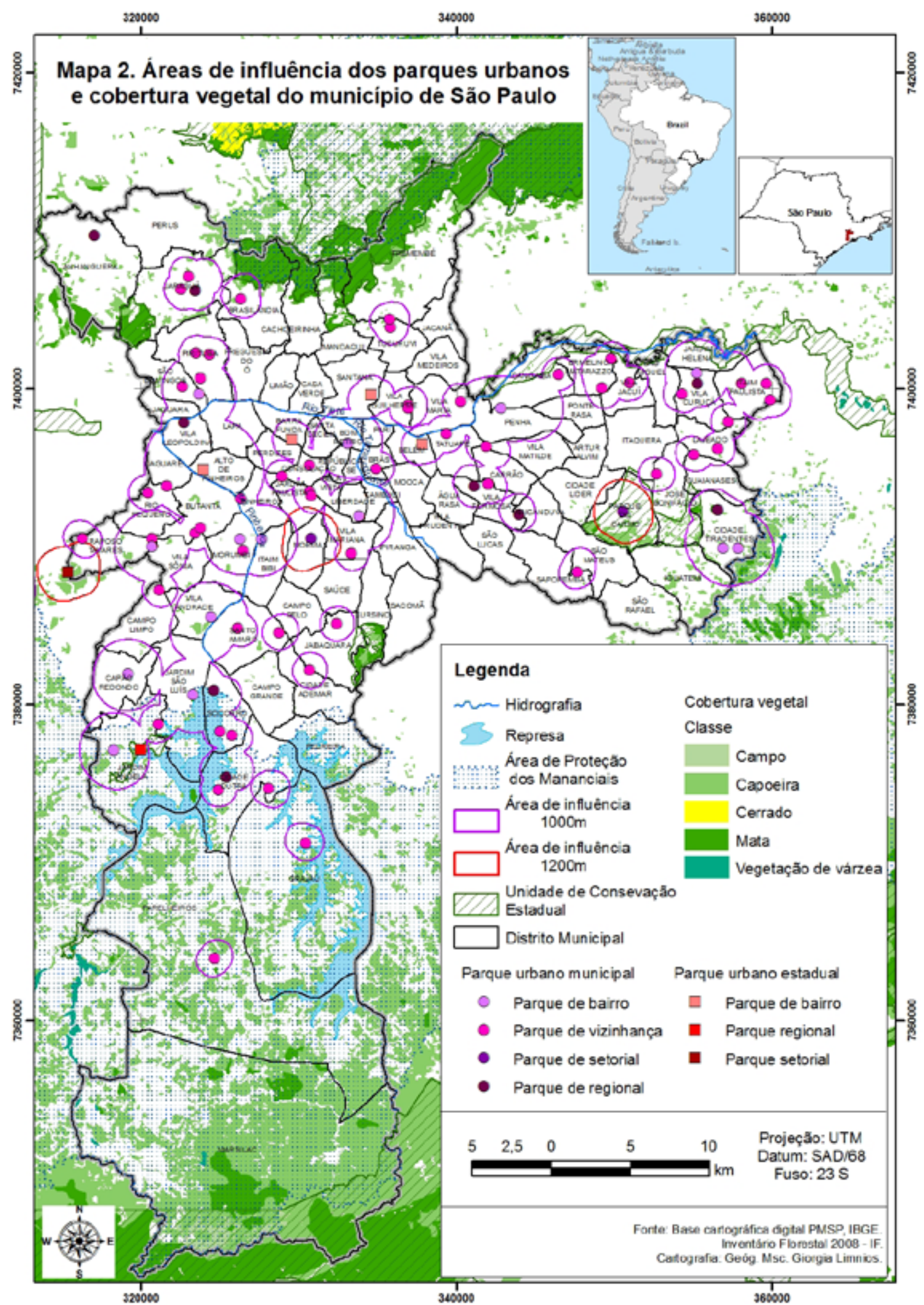

Mapa 2 - Áreas de influência dos parques urbanos e cobertura vegetal do município de São Paulo 
Há muito que caminhar na visão dos planejadores quanto a definir as dimensões ecológicas também aos parques urbanos, compatibilizando o uso social com funções ecológicas dos parques, particularmente nos parques regionais, de bairro e setoriais.

As áreas verdes urbanas se mostram de grande importância para a melhoria da qualidade de vida nas cidades, na medida em que propiciam diversos benefícios como a melhoria da qualidade do ar, um aumento da permeabilidade do solo, absorção de partícula de poeira, melhoria nas condições microclimáticas entre outros.

Entretanto apenas a existência de um alto número de áreas verdes na cidade não garante a qualidade de vida de seus habitantes, é necessário que haja também serviços de infraestrutura básicos como saneamento, coleta de lixo, variáveis essas que correspondem não só a qualidade de vida dos habitantes da cidade, mas também a qualidade ambiental, evitando problemas como a contaminação de solos, ou mesmo a degradação e poluição dessas áreas. Além disso a acessibilidade aos parques deveria ser critério importante, dai analisarmos o raio de influencia destes parques.

A cidade de São Paulo é caracterizada pela urbanização intensa e consolidada, restando poucos espaços para a implementação de novos parques. Atualmente tem havido um esforço por parte do poder público para contornar essa situação, através de projetos de novos parques urbanos como é o caso do programa 100 parque que vem sendo executado pela Secretária do Verde e do Meio Ambiente.

No mapa 3 percebe um eixo principal de área de influência dos parques urbanos existentes no sentido Oeste-Leste. Há ainda um corredor ao norte. Na região sul, no entanto percebe-se que não há qualquer influência dos parques urbanos uma vez que praticamente não existem parques em área suficiente em nenhuma das tipologias. Situação curiosa é a área de influência dos parques no entorno do reservatório Guarapiranga. Os dados sugerem que estes parques poderiam cumprir uma função ecológica importante nesta região de mananciais.

Existem parques que estão em obras e, outros planejados pelo governo municipal, os quais necessitam de ações para a implantação. Caso sejam concretizados, teremos uma situação melhor para a cidade de São Paulo, porém com algumas áreas sem influência de alguma tipologia de parque. Assim, sugerimos criar parques em todas as regiões da cidade para equilibrar a demanda social por áreas verdes.

O que pudemos observar através desse estudo é uma distribuição irregular das tipologias de parques e suas áreas de influencia no município de São Paulo, tendo uma concentração de unidades nas zonas oeste, centro e centro-sul do município respectivamente, em detrimento das demais áreas da cidade. $\mathrm{O}$ distrito de Parelheiros com um alto índice de 
cobertura vegetal remanescente da Mata Atlântica, distribuídos em diversos fragmentos, porém conectados entre si, e conectados também ao contínuo florestal existente em Marsilac, diminuindo assim consideravelmente o grau de fragmentação nessa região.

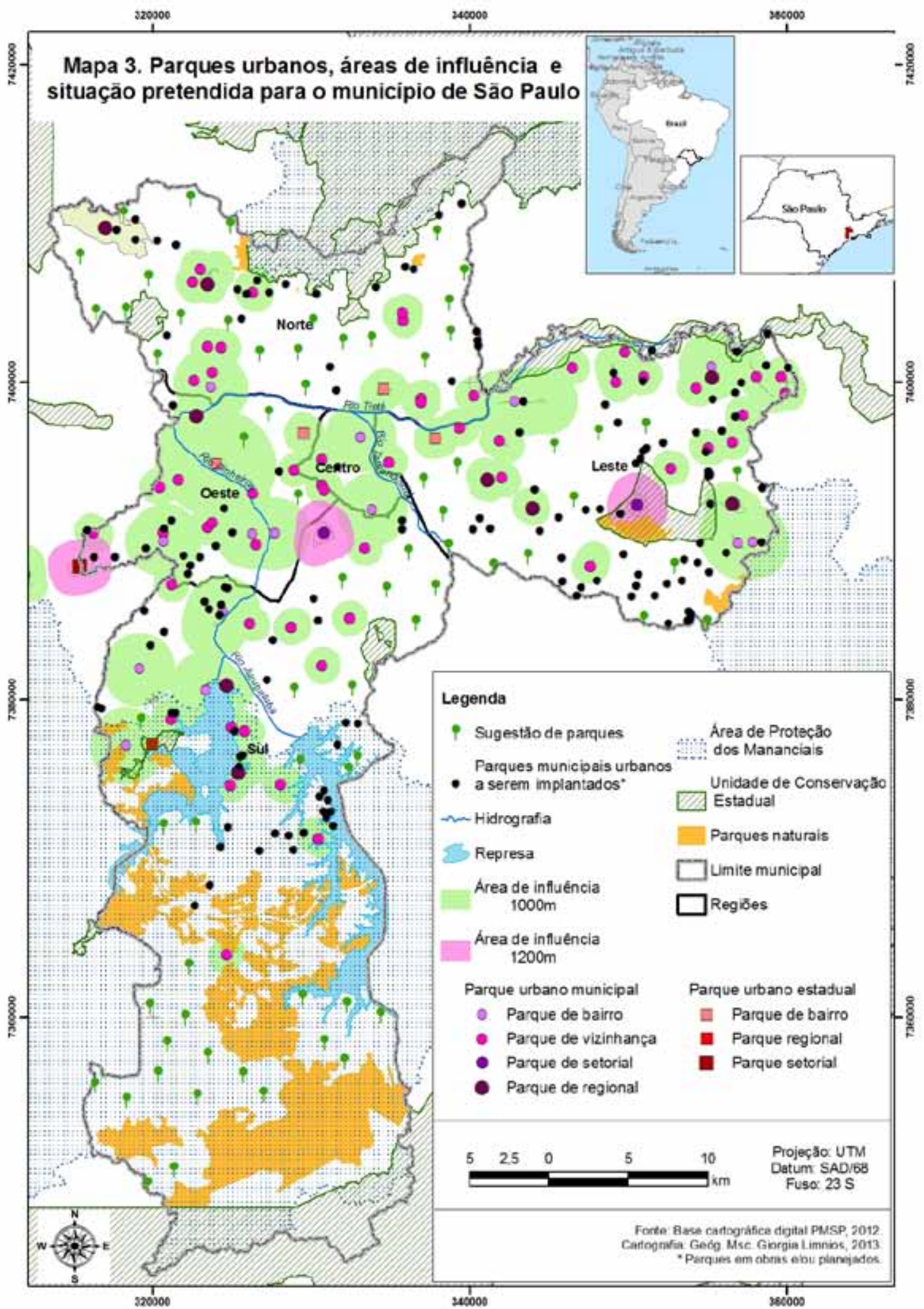

Mapa 3 - Parques urbanos, áreas de influência e situação pretendida para o município de São Paulo. 
Assim a análise espacial reflete uma política territorial caótica onde a funcionalidade das tipologias de parque vem sendo pouco considerada na criação de parques urbanos. Vemos também que as áreas onde ainda o potencial ecológico é importante como na zona leste, norte e sul as políticas não tem priorizado a criação de parques urbanos tirando partido dos remanescentes da cobertura vegetal original que ainda é possível observar nestas regiões.

- Diante destas análises sugerimos como propostas:

- Considerar a tripla função ecológica, lazer e estética na criação de novos parques urbanos;

- Priorizar parques regionais e setoriais nas regiões com maiores fragmentos de Mata Atlântica;

- Adequar a política de fluxos e transportes públicos considerando a existência de parques como equipamentos necessários a qualidade de vida urbana;

- Criar em cada distrito pelo menos um parque de bairro com um paisagismo baseado na vegetação nativa de São Paulo, mesmo que seja necessário desafetar quarteirões ocupados com edificações já existentes;

- Criar um mosaico de parques que representem os principais compartimentos de vegetação original do município, a saber, colinas e várzeas;

- Criar parques com infraestrutura adequada para a prática de variadas modalidades esportivas, além de atividades de educação ambiental e programações culturais.

Concluindo, é necessário que haja mais estudos sobre a distribuição das áreas verdes na cidade, para que esses possam servir de subsídios ás políticas publicas, podendo assim sugerir áreas prioritárias para a conservação e restauração, visando à conexão dessas áreas e a diminuição da fragmentação da paisagem, para assim garantir a efetividade e aumentar os benefícios que a vegetação pode trazer em relação à qualidade de vida dos habitantes dos grandes centros urbanos.

O Ideal é planejar um desenvolvimento urbano que concilie a implantação e interligação de áreas verdes, com o sistema de infraestrutura urbana buscando assim a melhoria da qualidade de vida nos grandes centros urbanos. 


\section{BIBLIOGRAFIA}

AB' SABER, A. São Paulo: ensaios entreveros. São Paulo: EDUSP, Imprensa Oficial do Estado de São Paulo, 2004.

CAVALHEIRO, F., DEL PICCHIA, P. C. D. Áreas verdes: conceitos, objetivos e diretrizes para o planejamento. In: ENCONTRO NACIONAL SOBRE ARBORIZAÇÃO URBANA, 4, 1992, Vitória/ES. Anais...vol.I. Vitória: 1992.p.29-38.

FURLAN, S. A. Paisagens Sustentáveis: São Paulo e sua cobertura vegetal. In: Geografias de São Paulo: a metrópole do século XXI. São Paulo: CONTEXTO, 2004.

Whately, M (Org). Parques urbanos municipais de São Paulo : subsídios para a gestão/ organização. São Paulo: Instituto Socioambiental, 2008.

KLIASS, R.G. Parques urbanos de São Paulo e sua evolução na cidade. São Paulo: PINI, 1993.

LIMNIOS, G. Repertório botânico de acompanhamento viário do bairro City Butantã. Dissertação de Mestrado.DG/USP, 2006.

MACEDO, S.S; SAKATA, F.G. Parques Urbanos no Brasil. São Paulo: EDUSP: Imprensa Oficial do Estado de São Paulo, 2003.

MELLO-THÉRY, N. A. de. Conservação de áreas naturais em São Paulo. Revista Estudos Avançados, vol.25, no.71. São Paulo Jan./Apr. 2011

SAINT-HILAIRE, A. de. Viagem à Província de São Paulo. Belo Horizonte: Itatiaia, São Paulo: EDUSP, 1976. 